\title{
Target-Oriented Clinical Skill Enhancement (TOCSE) Is an Effective Tool to Bridge Didactic to Clinical Learning: A Randomized, Controlled Trial
}

\author{
Leilani B. Mercado Asis, MD, PhD, MPH, MEd (DE); \\ Maria Victoria D. Garcia, MD; Ma. Charlene Ann V. Balili, MD; \\ Erick S. Mendoza, MD; Melvin R. Marcial, MD, MHPEd; \\ Estrellita J. Ruiz, MD, MHA
}

\begin{abstract}
Purpose: To connect didactic learning to clinical application is a challenging task both for the teachers and students. Target-Oriented Clinical Skill Enhancement (TOCSE) is a teaching and learning tool that integrates basic medical sciences at the clinical level. The authors sought to determine if TOCSE is effective in bridging didactic knowledge to clinical skill and enhancing the clinical performance of fourth year medical students.
\end{abstract}

Method: Between March 2021 and June 2021, in an online platform, the authors randomly allocated 141 fourth year medical students into the experimental $(n=12$ groups; $n=63)$ and control groups $(n=12$ groups; $n=78$ ). Participants in the experimental group underwent the TOCSE module workshop while the control group utilized the standard method of teaching. The actively teaching faculty staff blinded of group allocation were invited to assess case presentations using a standardized rubric. A survey was done by the students (experimental and control) to evaluate how they perceived TOCSE

Leilani B. Mercado-Asis, MD, PhD, MPH, MEd (DE) Imasis@ust.edu.ph

Department of Medicine, Faculty of Medicine and Surgery, University of Santo Tomas, Espana, Manila, Philippines to their performance and learning. Independent parametric t-test was performed to compare the clinical skill scores between the two groups.

Results: The experimental group had a mean clinical skill score of 35.29 (SD=2.64, excellent) while the control group had a mean clinical skill score of 31.96 (SD=4.04, satisfactory). The between-group comparisons using independent t-test indicated that the mean difference of -3.33 clinical skills scores between the experimental and control groups was statistically significant $(t=-2.39$, $p=0.026,95 \% \mathrm{Cl}=-6.22$ to -0.45$)$. Moreover, the perceived usefulness score (scale 10 as highest) among the TOCSE presenters (experimental groups) was 8.43 (SD=0.84) and scores among the TOCSE audience (control groups) was comparable at 8.36 $(S D=0.71)$, both of which were interpreted as very helpful.

Conclusion: TOCSE is effective in bridging didactic knowledge to clinical skill and enhancing clinical performance of fourth year medical students.

\section{INTRODUCTION}

It has been long recognized and reported up to the present that to connect didactic learning to clinical application is a challenging task both for the teachers and students.[1-7] Traditional medical curricula rely 
primarily on clerkships during the clinical period of study to train clinical skills, while the preclinical period is mainly used to teach the basic sciences. [7] Although clinical subjects have been already introduced in the second year and third year curricula, entering the arena of clinical application during the fourth year or clerkship creates an atmosphere of uncertainty, competence issue, disconnection, and space for poor organizational skills compounded by differences in the level of clinical mastery by teachers. $[3,6]$

In a systematic review by Surmon and colleagues, they were able to identify nine themes relating to the perceptions of preparedness among fourth year medical students as follows: 1) competence, 2) disconnection, 3) links to the future, 4) uncertainty, 5) part of the team, 6) time/workload, 7) adjustment, 8) curriculum, and 9) prior life experiences and learning.[6] Similar identified struggles have been reported by Lyss-Lerman and her group among interns whose fourth year clinical experiences were visaged with lack of medical knowledge, lack of selfreflection and improvement, poor organizational skills, and underdeveloped professionalism. [3]

This problem of students' struggles during the transition to clerkships has also been shown to reflect among clerkship directors. [5] The issues elaborated were understanding roles and responsibilities, adjusting to clinical cultures, performing clinical skills, learning the logistics of clinical settings, and encountering frequent changes in staff, settings, and content.[1] Interestingly, clerkship directors recognized students' struggles with roles and responsibilities, performing clinical skills, and adjusting to clinical cultures, but they also focused on students' difficulties applying knowledge to clinical reasoning and engaging in self-directed learning. [5] Wenrich, et al. further pointed out that students' expectations differ from faculty expectations which has been the cause of mounting students anxiety. Students had higher expectations than both faculty groups for advanced skills preparation. [4]

The clinical training curriculum in clerkship is embedded in the framing learning objectives outlined by Sahu and colleagues as one of the best practices to impart clinical skills. In such a platform, it was conspicuously emphasized on the development of a patient-centered approach and understanding the significance of pathophysiology in clinical presentations. To expand the modes of training, it has been instituted that medical schools must adapt essential teaching methods that will influence student learning of basic practical clinical skills apart from simulated learning, lectures, multimedia instruction, and problem-based learning.[7] Clarification of clinical skill expectations with training prior to clerkship with clear integration of basic curricula and alignment of faculty expertise has been suggested to alleviate student struggles and anxiety as they enter clerkship.[4] Although the foregoing publications and discussions have sorted out the needs and strategies to make clerkship a fruitful and enjoyable learning experience, there remains a gap on how to bridge didactic knowledge to clinical application in a more specific approach.

Target-oriented clinical skill enhancement (TOCSE) is both a teaching and student learning strategic tool designed to specifically address the need to connect didactic knowledge obtained during the undergrad years to clinical application during clerkship. $[8,9]$ The unique features of developed teaching and learning approach include-emphasis on the risk factors for contacting the primary disease, explanation of the pathophysiology of the chief complaint, and sign and symptom-based management of the patient's acute problem for immediate relief of patients. The chief complaint is further digested into its anatomy reflecting what diagnostic and laboratory work-up must be performed that will lead to resolution of the primary medical problem. In order to determine if TOCSE is effective in bridging didactic knowledge to the clinical skill of fourth year medical students and to determine if TOCSE is effective in enhancing and improving the clinical skill performance of fourth-year medical students, this research was undertaken. The conceptual framework of TOCSE is shown in Figure 1.

\section{METHOD}

\section{Research Design}

We utilized a randomized, controlled trial design at a single tertiary academic institution, Faculty of Medicine and Surgery (FMS), University of Santo Tomas (UST), from March 2021 to June 2021. The research platform is purely online.

We conducted random allocation of participants to receive the TOCSE (experimental) or the usual didactic method (control) using computer冈generated sequences of randomly permuted blocks (sizes 


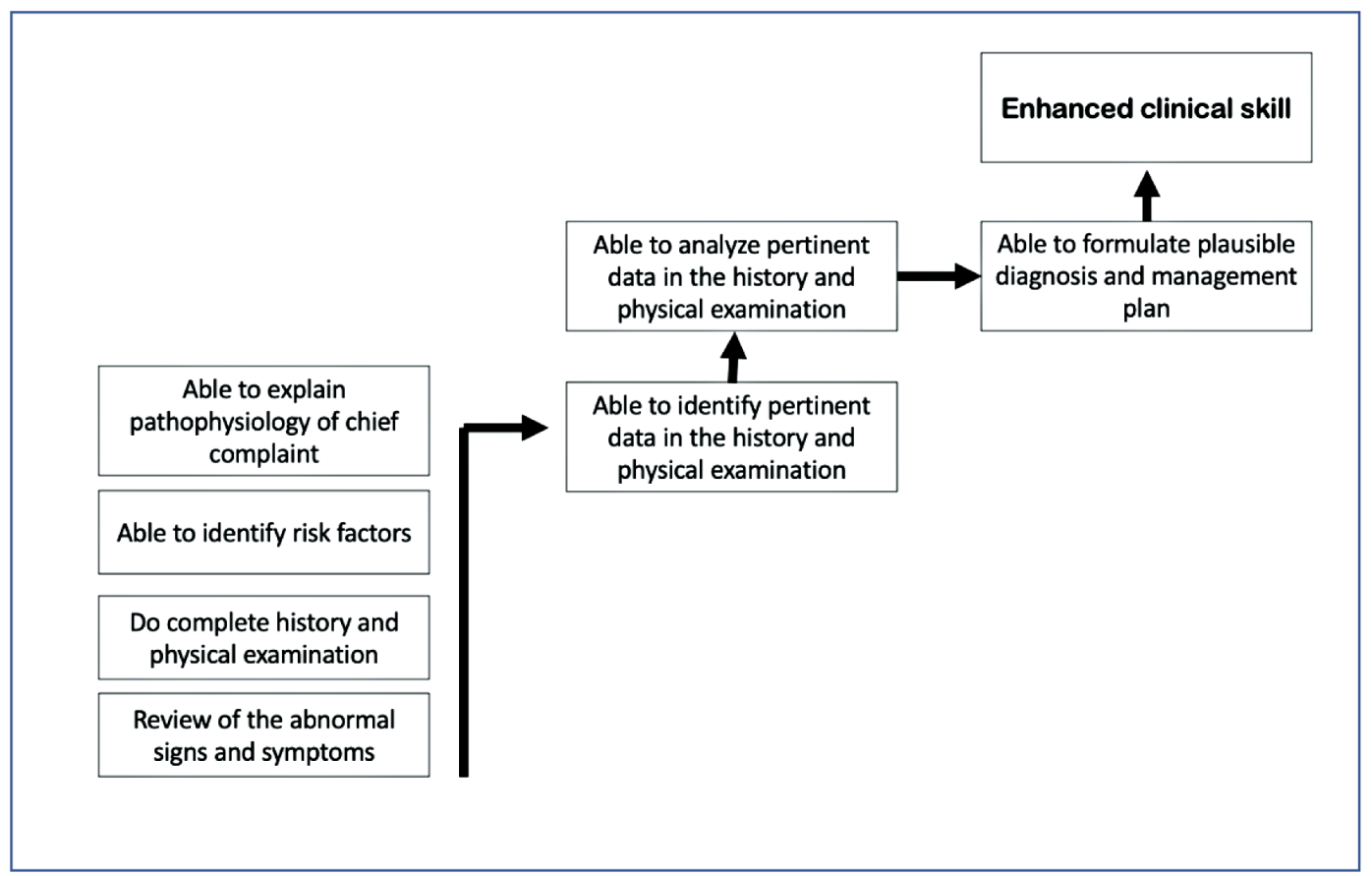

Figure 1. Concept map of the Target-Oriented Clinical Skill Enhancement (TOCSE)

of five or six) with a randomization ratio of $1: 1$. Randomization was carried out by an independent statistician and was stratified according to the week of module rotation. We employed the total enumeration approach, which is a technique involving all eligible participants thus, encapsulating all members of the target population. As such, sample size computation was not necessary since the study included all eligible members of the target population rather than just a sample.

\section{Sample and Setting}

The target population of this study was fourth year medical students who rotated to the endocrinology class. The study did not impose any exclusion criteria to gather as rich data as possible. The study employed the total enumeration approach, which is a technique that involves all eligible participants thus, encapsulating all members of the target population. As such, sample size computation was not necessary since the study included all eligible members of the target population rather than just a sample.

We applied the TOCSE experiment during the 2-hour online endocrinology class in a single session. We randomly assigned the groups of students to the experimental group and control group. The students were grouped into four, each group having four to five members. Two groups underwent TOCSE workshop (experimental group) and the other two did not (control group). All groups were assigned cases pertaining to various endocrine diseases. Only stem cases were given to the student groups where full cases were built up from history to management and follow-up plans. A pair of the experimental group and control group received the same stem case. The case assignments were given to students a week before the scheduled endocrine class session. The completed discussion of the cases were submitted in a written and PowerPoint forms and were presented orally during the online endocrine class hour.

\section{Data Collection}

We invited actively teaching faculty members from the Faculty of Medicine and Surgery who were blinded of group allocation to assess the presentations using a standardized rubric specifically formulated for the experiment (see Table 1).

There were two evaluators to each endocrine session day except in one where the class was rescheduled and the other staff was eventually not available. We excluded all co-authors of the TOCSE paper in the evaluation process. We also performed a survey among all the students (experimental and control) to evaluate how they perceived TOCSE in relation to their performance and learning. Since faculty evaluators were not specialists of the class content topics (Endocrinology), they were provided with checklists containing expected output from 
Table 1. Grading rubric for the assessment of study groups (experimental and control).

\begin{tabular}{|c|c|c|c|}
\hline $\begin{array}{c}9-10 \\
\text { EXCELLENT } \\
\text { (More than } 75 \% \text { of } \\
\text { the expected) }\end{array}$ & $\begin{array}{c}8-7 \\
\text { SATISFACTORY } \\
\text { (50-75\% of the } \\
\text { expected) }\end{array}$ & $\begin{array}{c}6-5 \\
\text { FAIR } \\
\text { (Less than } 50 \% \\
\text { to } 30 \% \text { of the } \\
\text { expected) }\end{array}$ & $\begin{array}{c}4-3 \\
\text { POOR } \\
\text { (Less than } 30 \% \\
\text { expected) }\end{array}$ \\
\hline
\end{tabular}

\footnotetext{
Application of basic knowledge.

Able to:

a. obtain pertinent history and physical examination

b. identify risk factors

c. explain pathophysiology of chief complaint

Formulation of diagnosis.

Able to:

a. diagnose primary disease

b. diagnose co-morbidities

Formulation of management plan

Able to:

a. formulate plan for the primary disease

b. formulate plan for the co-morbidities

Presentation and communication skill

Able to:

a. answer questions appropriately

b. present appropriate and relevant contents in the slides
}

the students and of pertinent data needed in the evaluation. The evaluators did the evaluation processes during the oral presentation in the online endocrine class hour. We forwarded the completed rubrics to the study statistician for analysis.

The Integration Activity is the platform where general assessment of learning will be performed. This platform is an approach on case analysis taught to the students during their second and third years of medical clinical learning. All facilitators involved were blinded on the assigned groups. Co-authors of the study were all excluded from grading of students.

\section{Data Analysis}

We performed statistical analyses of the data using Stata SE 13.1 for Windows (Stata Corp, College Station, Texas). A p-value of 0.05 was considered statistically significant. Descriptive statistics such as mean, standard deviation, frequency, and percentage were used to summarize the outcome variables. Inferential statistics, on the other hand, involves Analysis of Covariance (ANCOVA). We performed this test to compare the clinical skill scores between the experimental and control groups while controlling or adjusting for the effects of significant confounders.

\section{Ethical Considerations}

This study was conducted in accordance with international and national guidelines on research of human participants such as the Declaration of Helsinki, Good Clinical Practice, and the National Ethical Guidelines for Health and Health-Related Research (NEGHHRR) 2017. Considering that the study is an evaluation of the effectiveness of a teaching approach, which falls under the criteria for an exempted review (NEGHHRR, 2017), the researcher applied for an exempted review from the UST-FMS Research Ethics Committee.

\section{Conflict of Interest}

This study did not receive any financial support from any third party nor pharmaceutical company. Hence, this study has no financial conflict of interest to report. The researchers though affiliated with the study site did not participate as facilitators in the implementation of the research intervention.

\section{Privacy and Confidentiality}

Data collection forms did not inquire any personal identifier and used only control numbers. The gathered data were encoded in a password-encrypted 
computer and were de-identified. In addition, all electronic data associated with this study will be stored in this password-protected computer. Confidentiality will be assured by using the data and its results only upon agreed purposes and reasons. Only the researchers will have access to all research information and other relevant documents. All gathered data were reported as summative results. Data will be stored for a maximum of 3 years, and these will be properly disposed either through shredding of paper-based documents or through reformatting the electronic hardware for electronic data.

\section{Informed Consent and Recruitment Process}

This study employed a delayed consenting process due to the following reasons. First, the study participants were fourth year medical students and the researchers were professors of the academic institution, thus the former were considered vulnerable subjects due to imbalance of power in hierarchy. Second, securing informed consent would inevitably reveal potential group allocation to the participants, thus breaking the blinding process will lead to errors or bias due to participants' knowledge of the group allocation. Hence, the researchers employed a delayed informed consent process where informed consent was secured after data had been collected to mitigate potential coercion of participation and over- or under-performance of the participants during the assessment of outcome variables [Association of Clinical Research Professionals (ACRP), 2013]. Upon completion, the study and outcome variables had been assessed, the researchers secured consent from the participants to allow the former to utilize the data that had been collected (ACRP, 2013).

\section{Risks and Benefits}

The anticipated risks of this study were the possibility of breach in confidentiality and inconvenience due to the extra time needed by participants to participate in the TOCSE workshop. To minimize potential breaches in confidentiality, the previously mentioned data de-identification, data safety and security, and data storage and disposal measures were strictly observed. In contrast, to reduce inconvenience, the TOCSE workshop was scheduled in advance and done during the most convenient time and date agreed upon with the participants.

Despite these risks, the participants of the study have direct and indirect benefits from the participation in this study. The direct benefit is the potential improvement in the acquisition of clinical skills among participants. In addition, the indirect benefit of the study involves contribution of the study to knowledge about the effectiveness of the TOCSE module in improving clinical skills, thus allowing future academicians and clinicians to improve their teaching strategies and clinical practice, respectively, by incorporating the TOCSE module.

\section{Incentive or Compensation}

The participants, both the faculty evaluators and students, did not receive any monetary or nonmonetary compensation for their participation in this study.

\section{RESULTS}

There were 28 groups who completed the endocrine tasks. However, four groups (2 TOCSE experimental, 2 control) were not able to have their oral presentation because of cancellation of classes on the affected date. Therefore, we evaluated only 24 groups; 12 experimental $(n=63)$ and 12 control $(n=78)$, who were able to present orally. Another endocrine class schedule was moved to another date which affected availability of the two invited faculty evaluators. Only one replacement was able to attend the make-up class. Therefore, we had a total of 11 faculty evaluators who evaluated the 24 groups comprising a sum total of 141 students.

In Table 2 the descriptive statistics of clinical skills among medical students according to group allocation showed that those who received the TOCSE intervention ( $\mathrm{n}=12$ experimental groups; $\mathrm{n}=63$ ) had a mean clinical skill score of 35.29 $(S D=2.64)$, which we interpreted as excellent. In contrast, the control groups $(n=12$ control groups; $\mathrm{n}=78$ ) which did not receive the TOCSE intervention had a mean clinical skill score of 31.96 (SD=4.04), which we interpreted as satisfactory. The TOCSE experimental group had higher clinical skill scores than the control group.

The between-group comparisons of clinical skills among respondents in the TOCSE experimental 
Table 2. Descriptive statistics of clinical skills among medical students according to group allocation $(N=24)$

\begin{tabular}{lllll}
\hline \multicolumn{1}{c}{ Clinical Skills } & Mean & SD & $95 \% \mathrm{Cl}$ & $\begin{array}{c}\text { Verbal } \\
\text { Interpretation a }\end{array}$ \\
\hline TOCSE Experimental Group $(\mathrm{n}=12)$ & 35.29 & 2.64 & 33.61 to 36.97 & Excellent \\
Control Group $(\mathrm{n}=12)$ & 31.96 & 4.04 & 29.39 to 34.52 & Satisfactory \\
\hline
\end{tabular}

a Note: Score interpretation was categorized using Dedekind cut approach:

Poor skills: scores between 12.00 to 18.99 , Fair skills: scores between 19.00 to 25.99 , Satisfactory skills: scores between 26.00 to 32.99 ,

Excellent skills: scores between 33.00 to 40.00

Table 3. Between-group comparison of clinical skills between the TOCSE intervention (experimental) group and control groups $(\mathrm{N}=24)$

\begin{tabular}{|c|c|c|c|c|c|c|}
\hline \multirow[t]{2}{*}{ Outcomes } & \multicolumn{2}{|c|}{ Mean (SD) } & \multirow{2}{*}{$\begin{array}{c}\text { Mean } \\
\text { Difference }\end{array}$} & \multirow[t]{2}{*}{ t-value } & \multirow{2}{*}{$\begin{array}{c}\text { p-value } \\
\text { (Two-Tailed) }\end{array}$} & \multirow[t]{2}{*}{ Partial $\eta^{2}$} \\
\hline & $\begin{array}{l}\text { TOCSE Experimental } \\
\text { Group }(n=12)\end{array}$ & $\begin{array}{c}\text { Control Group ( } \mathrm{n}= \\
12)\end{array}$ & & & & \\
\hline Clinical Skills & $35.29(2.64)$ & $31.96(4.04)$ & -3.33 & -2.39 & 0.026 & $20.66 \%$ \\
\hline
\end{tabular}

Table 4. Descriptive statistics of perceived usefulness of TOCSE among medical students according to role in TOCSE intervention $(\mathrm{N}=141)$

\begin{tabular}{lcccc}
\hline Perceived Usefulness of TOCSE & Mean & SD & 95\% CI & Verbal Interpretation $^{a}$ \\
\hline TOCSE Presenter $^{b}(n=63)$ & 8.43 & 0.84 & 8.22 to 8.64 & Very Helpful \\
TOCSE Audience $^{c}(\mathrm{n}=78)$ & 8.36 & 0.71 & 8.20 to 8.52 & Very Helpful \\
\hline
\end{tabular}

a Note: Score interpretation was categorized using Dedekind cut approach:

Not helpful: scores between 0.00 to 2.49 , Somewhat helpful: scores between 2.50 to 4.99 , Moderately helpful: scores between 5.00 to 7.49 ,

Very helpful: scores between 7.50 to 10.00

${ }^{b}$ Experimental group

cControl group

groups and control groups using independent t-test are shown in Table 3 . The results indicated that mean clinical skills scores between the experimental and control groups was statistically different, with a mean difference of $-3.33(t=-2.39, p=0.026$, $95 \% \mathrm{Cl}=-6.22$ to -0.45$)$. This result denotes that the mean clinical skills score of those in the TOCSE intervention group (experimental group) was statistically higher than those in the control group. It can also be noted that the partial eta-squared $\left(\eta^{2}\right)$ was $20.66 \%$ (moderate effect size), indicating that $20.66 \%$ of the difference in clinical skills scores was attributed or due to the TOCSE intervention.

The descriptive statistics of perceived usefulness of TOCSE among medical students $(\mathrm{N}=141)$ according to their role in the TOCSE intervention is shown in Table 4. The mean perceived usefulness score among the TOCSE presenters (experimental group, $\mathrm{n}=63$ ) was $8.43(\mathrm{SD}=0.84)$, which means that these participants viewed TOCSE as very helpful in bridging didactic learning to clinical skills. Similarly, the mean perceived usefulness of TOCSE among the TOCSE audience (control group, $\mathrm{n}=78$ ) was 8.36
$(S D=0.71)$, which also denoted that TOCSE was very helpful in bridging didactic learning to clinical skills. Both the experimental and control groups perceived that TOCSE was very helpful in bridging didactic knowledge to clinical skills.

\section{DISCUSSION}

TOCSE is a developed teaching and learning strategic tool which brings the integration of basic medical sciences such as anatomy, physiology, biochemistry, pathology, and pharmacology at the clinical level. The primary goal is to bridge didactic knowledge to clinical skills among medical students at any level of clinical learning and application. The exemplary features of TOCSE as an added learning tool for clinical teaching are as follows: 1) emphasis on risk factors for contacting the primary disease, 2) explanation of the pathophysiology of chief complaint, 3) sign and symptom-based management of acute problem of the patient for immediate relief, 4) understanding and identifying all the targeted abnormal findings with allocated specific treatment, 


\section{ANATOMY OF THE CHIEF COMPLAINT}

Cough due to stimulation of the cough center from the production mucus coming from inflamed bronchus due to a pulmonary bacterial infection.

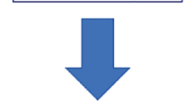

Mucolytic/nebulization

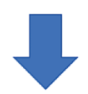

For immediate relief

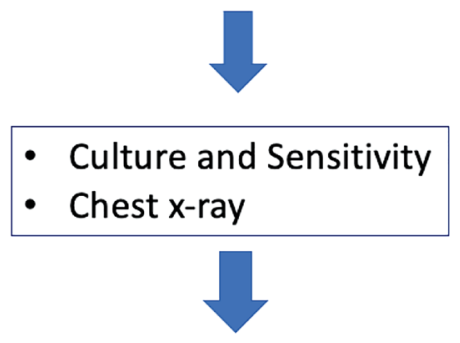

Tests for definitive diagnosis

Figure 2. Anatomy of the chief complaint from a patient who sought consult because of cough.

5) construction of TOCSE table that depicts the day to day clinical course of the patient and clearly showing the improvement and resolution of targeted abnormality/ties, and 6) daily prognostication of the medical situation based on treatment response.

Risk factors are specific for a certain age, gender, race, and family. They are specific and sensitive to a particular disease and are readily available to physicians at no cost. Risk factors are helpful in narrowing down diagnosis because of the specific individual predisposition. [10] This is very helpful for novice learners in the medical challenge of making a definitive diagnosis. In addition, Kalan and his colleagues reported that failure to identify risk factors causes delay in the diagnosis and timely treatment of patients.[11] It has also been elaborated that identification of risk factors, especially of general practitioners (GP), is critical.[12] Because the onset of noncommunicable diseases cannot be specifically discerned, risk factors are utilized to estimate temporal time of the disease onset like diabetes, hypertension, and obesity. The WHO uses risk factor assessment to address noncommunicable diseases.[13] Be that as it may, a student, however, must exercise caution when using risk factors of unproven diagnostic utility in medical diagnosis, as their presence may have little or no effect on disease probability.[1 11$]$ Nonetheless, Lobig and his group have demonstrated that in the presence of risk factors, extended work may be indicated. A medical setting example was a patient with microscopic hematuria to undergo mere ultrasound of the kidneys to an extended workup using cystoscopy, urinary cytology, and cross-sectional imaging of the upper urinary tract if the patient has the risk for malignancy. [14]

In the TOCSE learning tool, anatomy of the chief complaint has been introduced wherein explanation of its pathophysiology must reflect the acute problem, where medications or approach of management for immediate relief can be derived, and definitive diagnostic and management plans for the primary disease and comorbidities can be formulated (Figure 2). The construction of the concept maps by students for pathophysiology of the disease has been introduced in the basic subject of physiology in the first year curriculum and further elaborated for diagnosis and management of disease in the third year. Such a background has made it easier for the fourth year medical students to dissect the anatomy of the chief complaint as reflected in their perceived usefulness of the TOCSE learning tool. (Table 4)

Figure 3 shows an activity output from a group of clerks on how the narrative pathophysiology of the chief complaint has been derived from a concept map (A) with a detailed illustration of its anatomy (B) to depict the diagnostic and management plans for the case (C).

Chief complaint-based clinical performance measures offer the opportunity to assess quality and reflect the value of care delivered, especially in a medical situation that requires immediate relief of a patient suffering. Griffey and his group emphasized that although the diagnosis-centric approach allows 


\section{(A) Concept Map for Type 2 Diabetes Mellitus and Its Complications}

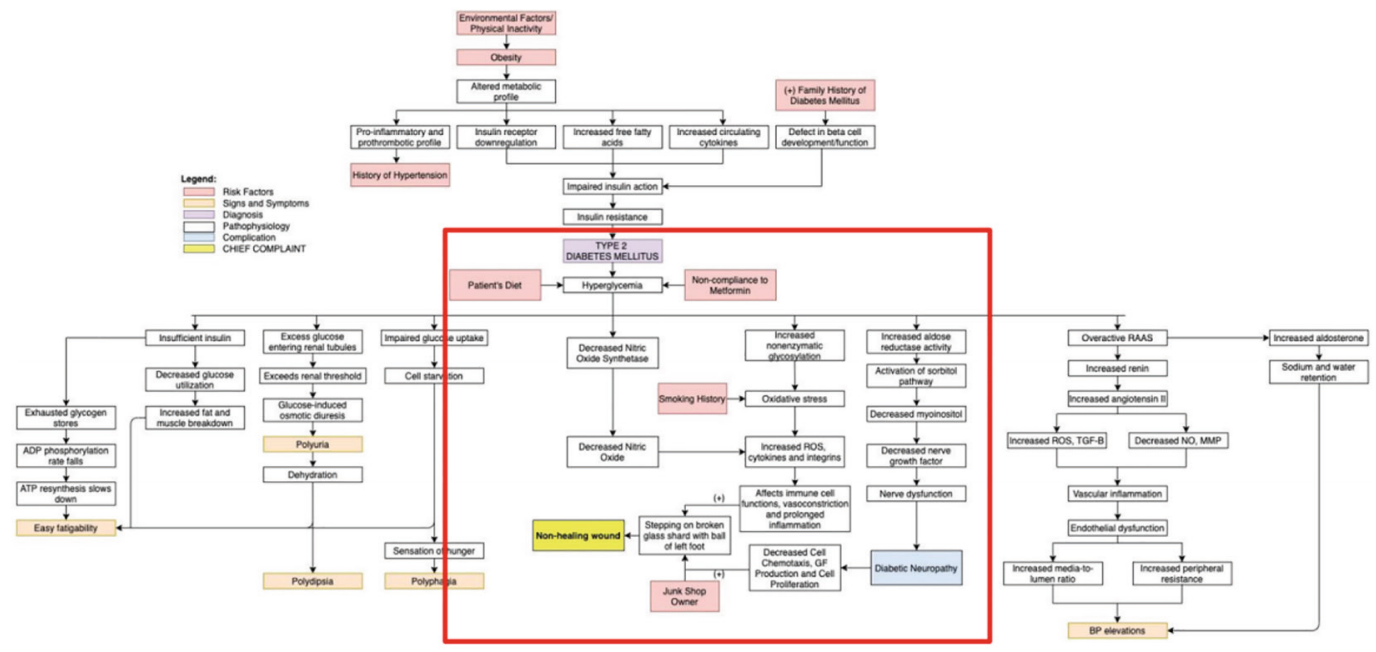

(C)

Pathophysiology of the Chief Complaint

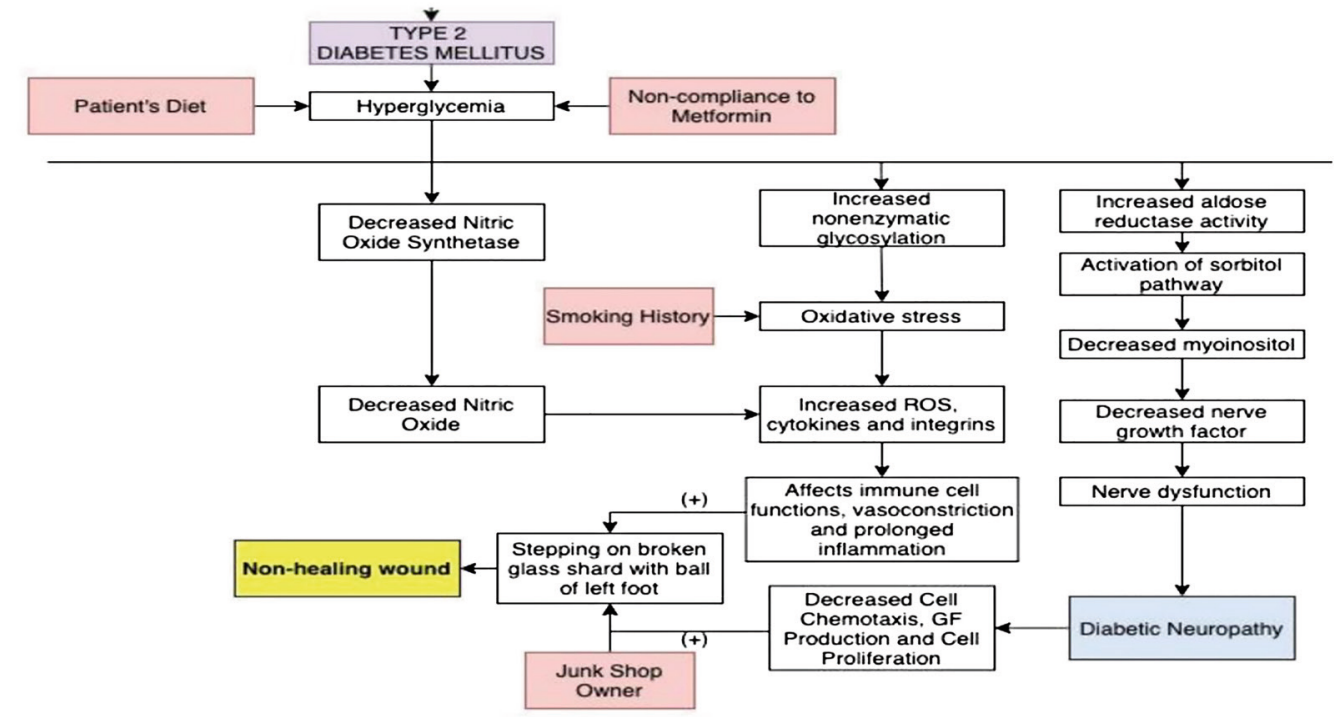

ROS - reactive oxygen species, GF - growth factor

(B)

\section{Debridement}

\section{Anatomy of the Chief Complaint}

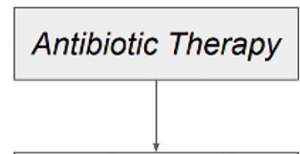
FBS and medication
adherence

Non-healing wound with pus formation, due to impaired wound healing process secondary to inadequate glycemic control and poor foot care with underlying diabetic neuropathy, further aggravated by smoking and lifestyle

Baltzis, D., Eleftheriadou, I., \& Veves, A. (2014). Pathogenesis and Treatment of impaired Wound Healing in Diabetes Mellitus: New

Figure 3. A. Concept map of the disease (type 2 diabetes mellitus), B. Pathophysiology of the chief complaint (non-healing wound), and C. Narrative of the pathophysiology and anatomy of the chief complaint depicting diagnostic, management, and therapeutic plans for the case (With permission from the students). 
the assessment of disease-specific quality, it fails to measure one of the primary functions of the emergency department (ER) care which involves diagnosing, risk-stratifying, and treating patients' potentially life-threatening conditions based on signs and symptoms.[15] Some chief complaints are accurate by definition (eg, shortness of breath), but others are not (eg, hematemesis that turns out to be hemoptysis). Therefore, providing diagnosis and explaining pathophysiology of the chief complaint may reduce the time interval to institution of immediate relief.[16]

In clinical application of the TOCSE teaching and learning tool, aside from emphasis on risk factors and pathophysiology of the chief complaint, every abnormal finding both in the history and physical examination must be well delineated and explained. A primary disease, differential diagnosis/es, and assessment of comorbidities must be completely reported. This particular TOCSE approach has addressed one of the common dilemma in clinical performance which is a multifactorial phenomenon. [17] There is confusion on which data to include, from the history of present illness, past medical history, psychosocial, personal, and family history, as well as relevant data in the physical examination. With the shortcomings of thorough history-taking and physical examination skills, it had been long reported that adequate medical problem-solving skills have decreased as well. $[18,19]$ More significantly, oversights of pertinent data in the history and physical examination may result in delayed diagnosis, unnecessary workups and testing, potentially harmful management, and escalated medical costs.[17]
One significant goal of the TOCSE approach is writing of the initial list of identified abnormal data in the history and physical examination of the patient which must be in consonance with the formulated concept map. This provides a framework that leads to specific diagnostic and management plans for the resolution or correction of every clinical abnormality. Resolution of clinical problems may be in hours, days, or weeks; nonetheless, the student's basic medical knowledge background is aptly applied.

Qualifiers for signs and symptoms were reviewed by the students (Figure 4). Students initially construct a table to demonstrate all the abnormalities obtained from the history and physical examination and target resolution of these entities with specific treatment. (Figure 5) These qualifiers were eventually utilized in the construction of the TOCSE table.(Figure 6) In the TOCSE table, the students could clearly delineate the effect of their specific management to the clinical course of the patient. Examples of student output (with permission and minor revision) are shown in Figures 4, 5, and 6. Students are encouraged to cite references of their report.

With the innovative TOCSE design to fill in the gap in transition from didactic to clinical learning of fourth year medical students, we have shown that, indeed, the strategic tool is the very reason why the performance of the TOCSE experimental group was excellent and statistically different compared to the control group ( $p<0.05$, Table 2). As mentioned in the foregoing discussion, it was noteworthy that the students themselves perceived that the strategic tool was very helpful in their learning. An agreeable stance has also been demonstrated by the TOCSE audience (control group) whose understanding

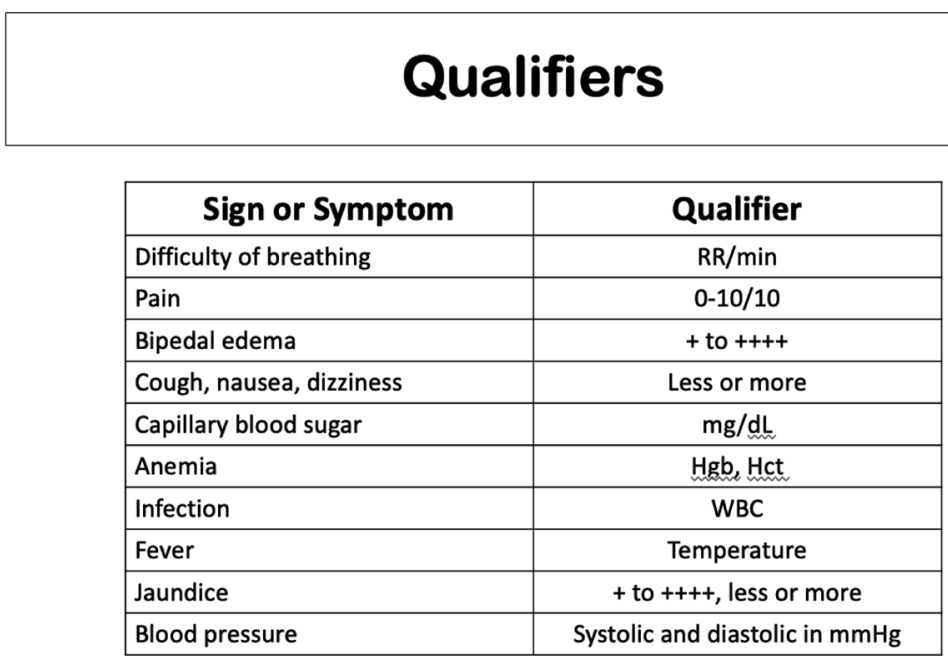

Figure 4. Qualifiers of signs and symptoms and other clinical features. 


\section{Targeted Abnormalities to Resolve}

\begin{tabular}{|c|c|c|c|}
\hline Signs/Symptoms & Abnormal Findings & Target/Goal & Treatment \\
\hline $\begin{array}{l}\text { Elevated Blood } \\
\text { Pressure }\end{array}$ & $140 / 90 \mathrm{mmHg}$ & $<130 / 80 \mathrm{mmHg}$ & Amlodipine $5 \mathrm{mg}$ OD \\
\hline Elevated blood glucose & $\begin{array}{l}\text { FBS } 180 \mathrm{~g} / \mathrm{dL} ; \mathrm{HbA} 1 \mathrm{c}: \\
7.5 \%\end{array}$ & $\begin{array}{l}\text { FBS: }<100 \mathrm{~g} / \mathrm{dL} ; \\
\mathrm{HbA} 1 \mathrm{c}:<7 \%\end{array}$ & \multirow[t]{2}{*}{$\begin{array}{l}\text { Metformin } 500 \mathrm{mg} \text { tab } \\
\text { BID PO }\end{array}$} \\
\hline $\begin{array}{l}\text { Diabetic neuropathy } \\
\text { (decreased sensation to } \\
\text { pain and light touch) }\end{array}$ & $\begin{array}{l}50 \% \text { decreased } \\
\text { sensation on both distal } \\
\text { lower extremities }\end{array}$ & $\begin{array}{l}\text { Improved sensation } \\
\text { on both distal } \\
\text { extremities }\end{array}$ & \\
\hline Skin ulcer & $\begin{array}{l}\text { Superficial ulcer on ball } \\
\text { of left foot with purulent } \\
\text { discharge, erythema ( } 1 \\
\mathrm{~cm}) \text { and } \\
\text { hyperpigmentation of } \\
\text { surrounding skin }\end{array}$ & $\begin{array}{l}\text { Complete healing of } \\
\text { wound }\end{array}$ & $\begin{array}{l}\text { Wound debridement } \\
\text { and wound care } \\
\text { Antibiotics } \\
\text { Co-amoxiclav } 625 \mathrm{mg} \\
\text { 2x a day }\end{array}$ \\
\hline
\end{tabular}

Bakris. (2020). Treatment of hypertension in patients with diabetes mellitus. Www.Uptodate.Com. https://www.uptodate.com/contents/treatment-of-hypertension-in-patients-with-diabetes-mellitus FBS - Fasting blood sugar; HbAlc - Glycosylated hemoglobin

Figure 5. Sample list of abnormalities to resolve with specific treatment.

TOCSE TABLE

\begin{tabular}{|c|c|c|c|c|c|c|}
\hline Problem & Target & Admission & Day 1 & Day 2 & Discharge (Day 5) & OPD Plan \\
\hline Superficial ulcer & $\begin{array}{l}\text { Signs of healing } \\
\text { on the wound } \\
\text { (e.g. presence of } \\
\text { granulation } \\
\text { tissue) } \\
\text { (-) Abcess }\end{array}$ & & $\begin{array}{l}\text { Debridement } \\
\text { successful }\end{array}$ & $\begin{array}{l}\text { Wound remains clean, } \\
\text { minimal purulent } \\
\text { discharge }\end{array}$ & $\begin{array}{l}\text { Wound has no more } \\
\text { purulent discharge, } \\
\text { minimal granulation } \\
\text { tissue formation } \\
\text { Wound c/S: S. } \\
\text { aureus, } \\
\text { methicillin-sensitive }\end{array}$ & \multirow{2}{*}{$\begin{array}{l}\text { Proper bandaging technique } \\
\text { (hydrogel bandage etc.), and } \\
\text { regular cleaning of wound with } \\
\text { povidone iodine } \\
\text { Mechanical off-loading, } \\
\text { Avoidance of walking barefoot, } \\
\text { Careful selection of footwear, } \\
\text { Daily inspection of the feet and } \\
\text { foot hygiene; Prompt } \\
\text { consultation if an abnormality } \\
\text { arises; Lifestyle changes such as } \\
\text { smoking cessation, dietary } \\
\text { modification (see elevated BP } \\
\text { and blood glucose rows) } \\
\text { Continue co-amoxiclav } 625 \mathrm{mg} \\
\text { for } 5 \text { days (see treatment row) }\end{array}$} \\
\hline $\begin{array}{l}\text { Decreased } \\
\text { sensation }\end{array}$ & $\begin{array}{l}\text { Minimal to no } \\
\text { expected } \\
\text { improvement }\end{array}$ & $\begin{array}{l}50 \% \text { sensory } \\
\text { deficit to light } \\
\text { touch, and pin } \\
\text { prick on both } \\
\text { lower leg and } \\
\text { feet (glove and } \\
\text { stocking } \\
\text { distribution }\end{array}$ & Same as admission & Same as admission & Same as admission & \\
\hline $\begin{array}{l}\text { Elevated blood } \\
\text { Pressure }\end{array}$ & $\begin{array}{l}\text { BP less than or } \\
\text { equal to } \\
130 / 80\end{array}$ & BP $140 / 90$ & BP $130 / 80$ & BP $130 / 80$ & BP $130 / 80$ & $\begin{array}{l}\text { Continue amlodipine (as shown } \\
\text { in the treatment section) and } \\
\text { emphasize the importance of } \\
\text { compliance and possible } \\
\text { complications if she does not } \\
\text { take her medications: } \\
\text { recommend decreased sodium } \\
\text { (no salt added in diet) }\end{array}$ \\
\hline Treatment & & $\begin{array}{l}\text { Wound debridement (referrral to } \\
\text { PRAS) } \\
\text { Wound Cis } \\
\text { Start on Co-amoxiclar } 625 \mathrm{mg} \\
\text { BiD, Mettormin } 500 \mathrm{mg} \text { SID. } \\
\text { Ammodipine } 005 \mathrm{mg} \text { PO. } \\
\text { Atorvastatin } 10 \mathrm{mg} \text { BID. }\end{array}$ & 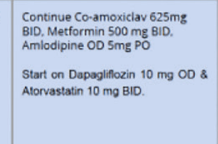 & 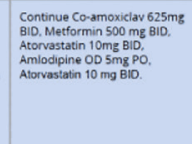 & 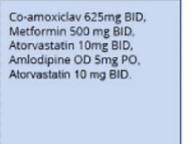 & \\
\hline
\end{tabular}

Figure 6. Sample TOCSE table (TOCSE, Target-Oriented Clinical Skill Enhancement).

of the discussion was likewise facilitated by the TOCSE tool utilized by the TOCSE experimental group. Furthermore, in the submitted reflection (data not shown) the students in the TOCSE intervention group explicitly expressed that they obtained extra confidence in completing the task from the preparation to oral presentation.

Because of the pandemic, the TOCSE experiment was done in a fully online platform. A virtual approach indeed may not be ideal to address clinical skill 
development and is admittedly very challenging. During the pandemic, many virtual curricula for medical students were shifted to asynchronous assignments, text and video resources, and independent study. Unfortunately, several medical institutions globally struggled to approximate the advantages of a conventional clinical setting to afford clinical skill development, particularly for fourth year students. [20-23]

In the commentary of Mian and Khan, teleteaching and telemedicine have been considered as alternatives to clinical placements where clinical knowledge could be retained.[23] However, Akers, Blough, and lyer expressed their concern on missed opportunities to be mentored by specialty faculty and perform clinical activities that entail decision-making. Moreover, it has been reported that students in the clinical clerkship program still preferred the hospital setting and were very much willing to participate as preliminary healthcare providers.[22]

The aforementioned discussion dichotomized two distinguished areas of clinical development among fourth year medical students; one is utilizing basic knowledge to develop clinical skill acumen, and second is the application of clinical skill acumen to a real-world setting. The latter may not be totally fulfilled in a teleteaching approach; however, the feasibility to accomplish the former has been clearly demonstrated in the results of our TOCSE experiment. Concurring to our finding was a report by Geha and Dhaliwal where in their analysis of a pilot study of various virtual teaching approaches in clerkship curriculum, the most highly rated exercises and cited "major improvements" by the fourth year students in their diagnostic assessments were drafting schemas and writing diagnostic assessments. Comparatively, similar to the TOCSE activity, major factors for the outcome of their study was reported to be an advance internal medicine knowledge, clinical reasoning skills, and formulating frameworks for clinical problems.[21]

The TOCSE strategic approach for both teaching and learning has clearly addressed several of the concerns and struggles of students during a transition from preclinical to clerkship level.[1-7] Specifically these are uncertainty, disconnection, competence issue, prior life experiences and learning, frequent changes in staff, changes in setting, and changes in content which could create surmountable anxiety among these learners. $[1,4,6]$ The lack of sufficient practical training has even dragged these problems through entry into internship as reported by Deghani, et al. [5] With one standardized TOCSE approach in whatever stage of learning, a medical student can now be uniformly assessed. Once again, Sahu and colleagues have emphasized that no matter what teaching method has been applied, the best practice of clinical skill development still involves patientcentered approach with depth in understanding the pathophysiology of each clinical feature of a disease.[7] Although effective performance in clinical settings requires the integration between theory and practice, there remains a gap between theoretical knowledge as taught in the classroom and what students experience in clinical settings.[24] With a clear clarification and definition of expectation on students at the preclinical level and utilization of the TOCSE strategic teaching and learning tool, there could be resolution and alleviation of the students' struggles and apprehension.[1-7] The developed competence and confidence will be instrumental for continued acquisition of improved clinical skills and performance.

In summary, TOCSE is a strategic teaching and learning tool that can bridge didactic knowledge to clinical skill of fourth year medical students. In addition, TOCSE has shown to effectively enhance and improve students' clinical skill performance.

\section{Disclosures}

Funding/Support: None

Conflicts of Interest: None

Ethical approval: The ethical approval has been waived by the University of Santo Tomas, Faculty of Medicine and Surgery (UST-FMS) Research Ethics Committee.

Disclaimers: None

Previous presentations: None 


\section{REFERENCES}

1. O'Brien B, Cooke M, Irby DM. Perceptions and attributions of third year student struggles in clerkships: do students and clerkship directors agree? Acad Med. 2007;82:970-8.

2. Frellsen SL, Baker EA, Papp KK, Durning SJ. Medical school policies regarding struggling medical students during the internal medicine clerkships: results of a national survey. Acad Med. 2008;83:876-81.

3. Lyss-Lerman P, Teherani A, Aagaard E, Loeeser H, Cooke $M$, Harpeer GM. What training is needed in the fourth year of medical school? Views of residency program directors. Acad Med. 2009;84:823-9.

4. Weinrich $M$, Jackson MB, Scherpbier AJ, Wolfhagen $I H$, Ramsey PG, Goldstein EA. Ready or not? Expectations of faculty and medical students for clinical skills preparation for clerkships. Med Educ Online. 2010; 15:5295.

5. Dehghani $M$, Athar $O$, Ashourioun V, Akhlaghi M, Avizhgan $M$, Esmaeili $A$, et al. A transitional curriculum for preparing medical students for internship, does it work? J Res Med Sci. 2013;18:506-9.

6. Surmon L, Bialoceerkowski A, Hu W. Perceptions of preparedness for the first medical clerkship: a systematic review and synthesis. BMC Med Educ. 2016;16:89.

7. Sahu PK, Chattu VK, Rewatkar A, Sakhamuri S. Best practices to impart clinical skills during preclinical years of medical curriculum. Journal of Education and Health Promotion. 2019;8:57.

8. Mercado-Asis LB. Introducing TOCSE: A tool to bridge didactic learning to clinical application (Part 1). Journal of Medicine UST. 2018;1:133-5. Available from: http:// dx.doi.org/10.35460/2546-1621.2017-0098

9. Mercado-Asis LB. Introducing TOCSE: A tool to bridge didactic learning to clinical application (Part 2). Journal of Medicine UST. 2019;3:313-7. Available from: http:// dx.doi.org/10.35460/2546-1621.2019-0023

10. Boyko EJ, Alderman BW. The use of risk factors in medical diagnosis: Opportunities and cautions. Journal of Clinical Epidemiology. 1990;43:851-8.

11. Kalan ME, Sis HY, Kelkar V, Harrison SH, Goins GD, Jafarabadi $M$, et al. The identification of risk factors associated with patient and healthcare system delays in the treatment of tuberculosis in Tabriz, Iran. BMC Public Health. 2018;18:174-84.

12. Grady A, Carey M, Oldmeadow C, Bryant J, Mazza D, Sanson-Fisher R. GP detection of health risk factors among general practice patients at risk of primary and secondary stroke. Family Practice. 2015;32:336-42.

13. WHO 2009. Risk factors assessment and screening procedure. Available from: http://origin.wpro.who.int/philippines/publications/module2.pdf

14. Lobig N, Wezel F, Martini T, Schroppel B, Bolenz C. (Article in German). Microscopic hematuria: Reasonable and riskadapted diagnostic. Urologe A. 2017;56:1139-46.

15. Giffrey RT, Pines JM, Farley HL, Phelan, MP, Beach CB, Schuur JD, et al. Chief complaint-based performance measures: A new focus for acute care quality measurement. Annals of Emergency Medicine. 2015;65:387-95.

16. Mowafi H, Dworks D, Bisanzo M, Hansoti B, Seidenberg P, Obermeyer Z, et al. Making recording and analysis of chief complaint a priority for global emergency care research in low-income countries. Academic Emergency Medicine. 2013;20:1241-5.

17. Faustinella F. Jacobs JR. The decline of clinical skills: A challenge for medical schools. Int J Med Educ. 2018;9:195-7.

18. Elstein AS, Shulman LS, Sprafka SA, Medical problem solving: an analysis of clinical reasoning. Cambridge, MA: Harvard Press; 1978.

19. Kassirer JP, Gorry GA, Clinical problem solving: a behavioral analysis. Ann Intern Med. 1978;89:245-55.

20. Akers A, Blough C, lyer MS (April 23, 2020) COVID-19 implications on clinical clerkships and the residency application process for medical students. Cureus 12(4):e7800. DOI: $10.7759 /$ cureus.7800

21. Geha R, Dhaliwal G. Pilot virtual clerkship curriculum during the COVID-19 pandemic: Podcasts, peers and problem solving. Med Educ. 2020;54(9):855-6.

22. Kim SM, Park SG, Jee YK, Song IH. Perception and attitudes of medical students on clinical clerkship in the era of the Coronavirus Disease 2019 pandemic. Med Educ Online. 2020;25:1809-929. Available from: https://doi. org/10.1080/10872981.2020.1809929

23. Mian A, Khan S. Medical education during pandemics: $A$ UK perspective. BMC Medicine. 2020;18:100. Available from: https://doi.org/10.1186/s12916-020-01577-y

24. Hashemiparast $M$, Negarandeh $R$, Theofanidis D. Exploring the barriers of utilizing theoretical knowledge in clinical settings: A qualitative study. Int J Nurs Sci. 2019;399-405.

(i) Open Access This article is licensed under a

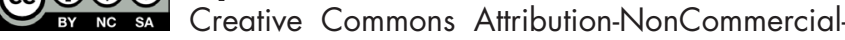
ShareAlike 4.0 International License, which permits use, share - copy and redistribute the material in any medium or format, adapt - remix, transform, and build upon the material, as long as you give appropriate credit, provide a link to the license, and indicate if changes were made. You may do so in any reasonable manner, but not in any way that suggests the licensor endorses you or your use. You may not use the material for commercial purposes. If you remix, transform, or build upon the material, you must distribute your contributions under the same license as the original. You may not apply legal terms or technological measures that legally restrict others from doing anything the license permits. The images or other third party material in this article are included in the article's Creative Commons license, unless indicated otherwise in a credit line to the material. If material is not included in the article's Creative Commons license and your intended use is not permitted by statutory regulation or exceeds the permitted use, you will need to obtain permission directly from the copyright holder. To view a copy of this license, visit https://creativecommons.org/licenses/by-nc-sa/4.0/. 